\title{
RESEARCH
}

Open Access

\section{Analysis of the risk and risk factors for injury in people with and without dementia: a 14-year, retrospective, matched cohort study}

Ruey Chen ${ }^{1,2}$, Wu-Chien Chien ${ }^{3,4,5}$, Ching-Chiu Kao ${ }^{2,6}$, Chi-Hsiang Chung ${ }^{5,7}$, Doresses Liu' ${ }^{6}$ Huei-Ling Chiu ${ }^{8}$ and Kuei-Ru Chou ${ }^{1,2,9^{*}}$ (D)

\begin{abstract}
Background: Most previous studies on dementia and injuries have focused on a particular type of injury, and few studies have investigated overall injury in people with dementia. In this study, we investigated the risk factors and risk of overall injury, including the diagnosis, cause, and intentionality of injury, in people with and without dementia in Taiwan.

Methods: We collected relevant data between 2000 and 2013 from the National Health Insurance Research Database (NHIRD). Overall, 455,630 cases, consisting of 91,126 people with dementia and 364,504 people without dementia, were included in this study and we performed subgroup analysis. A multivariate Cox proportional hazards regression analysis was used to determine the risk of injuries.

Results: The 14-year follow-up data showed that people with dementia had a higher risk of injury-related hospitalization than did people without dementia (19.92\% vs 18.86\%, hazard ratio $(H R)=1.070, p<0.001)$. Regarding the cause of injury, people with dementia were more likely to be hospitalized due to suffocation ( $H R=2.301, p<0.001)$, accidental drug poisoning ( $H R=1.485, p<0.001)$, or falls ( $H R=1.076, p<0.001$ ), and were less likely to be hospitalized due to suicide or self-inflicted injury $(H R=0.670, p<0.001)$ or a traffic accident $(H R=0.510, p<0.001)$ than were people without dementia. Subgroup analysis showed that people with dementia with any of the three subtypes of dementia were at a higher risk of homicide or abuse than were people without dementia (vascular dementia, $\mathrm{HR}=2.079, p<0.001$; Alzheimer's disease, $H R=1.156, p<0.001$; other dementia, $H R=1.421, p<0.001$ ). The risk factors for overall injury included dementia diagnosis, female gender, age 65-74 years, and seeking medical attention for an injury within the past year.

Conclusion: People with dementia are at a higher risk of injury-related hospitalization than people without dementia. The results of this study provide a reference for preventing suffocation, drug poisoning, and falls in people with dementia. In addition, government agencies should pay attention to and intervene in cases of abuse suffered by people with dementia.
\end{abstract}

Keywords: Injury, Dementia, Suffocation, Accidental drug poisoning, Falls, Suicide, Traffic, Abuse

\footnotetext{
* Correspondence: kueiru@tmu.edu.tw

'Department of Nursing, Taipei Medical University-Shuang Ho Hospital,

No.291, Zhongzheng Rd., Zhonghe District, Taipei 23561, Taiwan

${ }^{2}$ School of Nursing, College of Nursing, Taipei Medical University, No.250,

Wu-Hsing Street, Taipei 11031, Taiwan

Full list of author information is available at the end of the article
}

(c) The Author(s). 2018 Open Access This article is distributed under the terms of the Creative Commons Attribution 4.0 International License (http://creativecommons.org/licenses/by/4.0/), which permits unrestricted use, distribution, and reproduction in any medium, provided you give appropriate credit to the original author(s) and the source, provide a link to the Creative Commons license, and indicate if changes were made. The Creative Commons Public Domain Dedication waiver (http://creativecommons.org/publicdomain/zero/1.0/) applies to the data made available in this article, unless otherwise stated. 


\section{Background}

There are now more than 47 million people with dementia worldwide, and this number is expected to rise to 131 million by 2050 [1]. Dementia comprises a group of symptoms that includes progressive decline in cognitive function, memory, language skills, spatial perception, computational capability, judgment and decision-making, abstract thinking, problem solving, attention, and even vision, balance, feeling and sensory skills, and motor skills [2-5]. Moreover, people with dementia may exhibit disturbing behavior, including sleep problems, paranoia/delusion, diurnal disturbance, aggressiveness, and personality changes; the condition can be so severe that it will interfere with their personal relationships and their ability to engage in daily activities [6-8].

Injury is a public health problem worldwide and has become a leading cause of death as lifestyles continue to evolve. Moreover, injury may cause long-term disability and severe trauma [9]. In Taiwan, according to the International Classification of Diseases, Ninth Revision, Clinical Modification (ICD-9-CM), injury is classified into three categories based on the following: 1) the nature of the injury: N-code (800-999), including fractures, dislocations, injuries, open wounds, contusions, crush injuries, burns, and poisoning, which facilitate clinical diagnosis and treatment; 2) the external cause of the injury: E-code (E800-E999), including traffic and transport accidents, food or drug poisoning, poisoning by other substances (solid, liquid, gas, vapor), fall, fire and flame, drowning and suffocation, suicide and self-injury, homicide, natural environment, accidents during medical procedures, and injury due to law enforcement or war; these causes of injury can help develop injury prevention programs; and 3) supplemental description: in case of N-code 800-999, an E-code (for external cause of injury) should be specified to indicate unintentional injury (E800-E949) or intentional injury (E950-E969) [10].

The cognitive function and performance of people with dementia declines over time, which may result in an increased risk of injuries. Therefore, it is essential to investigate the risk of injuries in people with dementia. However, most previous studies on dementia and injuries focused on a particular type of injury, such as suffocation, accidental falls, accidental drug poisoning, homicide or abuse, suicide and self-inflicted injury, and traffic accidents. Studies on suffocation showed that food infarctions were positively correlated with dementia and that people with dementia were prone to suffocation caused by foreign bodies $[11,12]$. Moreover, among people with dementia, most cases of drug poisoning were accidental but were more severe than those in people without dementia $[13,14]$. Studies showed that the risk of falls was 2-8 times higher in people with dementia than it was in healthy individuals $[3,15,16]$. Moreover, studies showed that $5 \%$ to $55 \%$ of people with dementia suffered homicide or abuse, whereas only $3.2 \%$ to $27.5 \%$ of general elderly individuals suffered abuse $[17,18]$. For self-inflicted injury and traffic accidents, researchers have yet to reach an agreement. Recent publications indicate that people with dementia have a relatively high suicide rate in the early stages after dementia diagnosis $[19,20]$; however, people with moderate to severe dementia have a decreased risk of suicide [21, 22]. People with dementia are 2-10 times more likely to die from traffic accidents than are people without dementia [4]; however, some studies have shown that people with dementia are at lower risk of traffic accidents than the general population [23]. These studies focused on a single type of injury and did not investigate overall injury or the risk factors for injuries in people with dementia. In this study, we investigated overall injury, including the diagnosis, cause, and intentionality of injury, and the risk factors for injuries in people with and without dementia.

\section{Methods}

\section{Data sources}

We collected relevant data from the National Health Insurance Research Database (NHIRD). National Health Insurance (NHI) was implemented in 1995 in Taiwan, and almost all residents are now covered (coverage rate: $>99 \%$ ). The NHIRD is a database that was created for healthcare research institutes and includes information on the outpatient care, emergency treatment, and hospitalization of insured individuals. The diagnostic codes in the NHIRD are entered by physicians according to the ICD-9-CM. In this study each person with dementia was diagnosed by a neurologist or psychiatrist.

\section{Study design and sampled participants}

This was a retrospective, matched cohort study. Hospitalized people who had been diagnosed with dementia between 1 January 2000 and 31 December 2013 were included as three subtypes: 1) Alzheimer disease (i.e., senile dementia, presenile dementia, presenile dementia uncomplicated, presenile dementia with delirium, presenile dementia with delusional features, presenile dementia with depressive features, senile dementia with delusional or depressive features, senile dementia with delusional features, senile dementia with depressive features, senile dementia with delirium, and Alzheimer's disease); 2) vascular dementia (i.e., arteriosclerotic dementia, arteriosclerotic dementia uncomplicated, arteriosclerotic dementia with delirium, arteriosclerotic dementia with delusional features, and arteriosclerotic dementia with depressive features); and 3) other dementias (i.e., other specified senile psychotic conditions, and unspecified senile psychotic conditions). People who had been diagnosed with dementia prior to 2000, had a history of injury, or were younger than 50 years of age were excluded from this study. Each person with dementia was matched with four people without dementia according to gender, age group, and index year. The covariates included gender and 
age group (Fig. 1). Since the data were pseudonymized on the basis of a pro-con analysis to protect people's privacy, informed consent was waived. This retrospective analysis study was approved by the Joint Institutional Review Board of the Tri-Service General Hospital (TSGH IRB no. 1-105-05-142).

\section{Comorbidity}

Baseline comorbidities included diabetes mellitus, hypertension, hyperlipidemia, cerebrovascular disease, chronic kidney disease, and alcohol-related disease.

\section{Outcome measures}

The outcome measures were people who were admitted to hospital for injuries, including fractures, dislocations, sprains and strains, intracranial/internal injuries, open wounds, injury to blood vessels, superficial injuries/contusions, crush injuries, foreign body entering through an orifice, burns, injury to nerves and spinal cord, poisoning, and other injury, or coverage discontinuation.

\section{Statistical analysis}

IBM SPSS v22 (IBM Corp., Armonk, NY, USA) was used for statistical analysis. Continuous variables are expressed as the mean \pm standard deviation and analyzed with a $t$ test; categorical variables are expressed as $n$ (\%) and analyzed with a Chi-square test. Multivariate Cox proportional hazards regression analysis was used to determine the risk of injuries, and the results are presented as hazard ratios (HRs) with 95\% confidence intervals (CIs). The Kaplan-Meier method with a log-rank test was used to compare the risk of injuries between people with and without dementia. A $p$ value $<0.05$ was considered statistically significant.

\section{Results}

\section{Characteristics of people with and without dementia}

Table 1 shows that 455,630 individuals were included in this study, including 91,126 people with dementia-Alzheimer dementia 69,510 (76.28\%), vascular dementia 1385 (1.52\%), other dementia 20,231 (22.20\%) - and 364,504 people without dementia. Of these, 237,945 (52.22\%) were males, and $215,435(47.28 \%)$ were aged 75 to 84 years. People with dementia had received more medical attention at clinics or emergency rooms in the last year for a previous injury than people without dementia $(32.97 \%$ vs $30.76 \%, p<0.001)$, and people with dementia had a higher percentage of cerebrovascular disease $(13.33 \%$ vs $9.54 \%, p<0.001)$ or alcohol-related disease $(0.22 \%$ vs $0.16 \%, p<0.001)$ than people without dementia. There were no significant differences between the groups in terms of gender and age distribution after propensity score matching.

\section{Injuries and characteristics analysis}

Table 2 shows the injury-related hospitalization rates. A higher percentage of people with dementia than people without dementia were hospitalized due to injury (19.92\% vs $18.86 \%, p<0.001)$. Further analysis of the diagnosis, cause, and intentionality of injuries showed that fracture was the most common diagnosis in both people with dementia and people without dementia ( $35.12 \%$ vs $38.49 \%$ ); falls were the

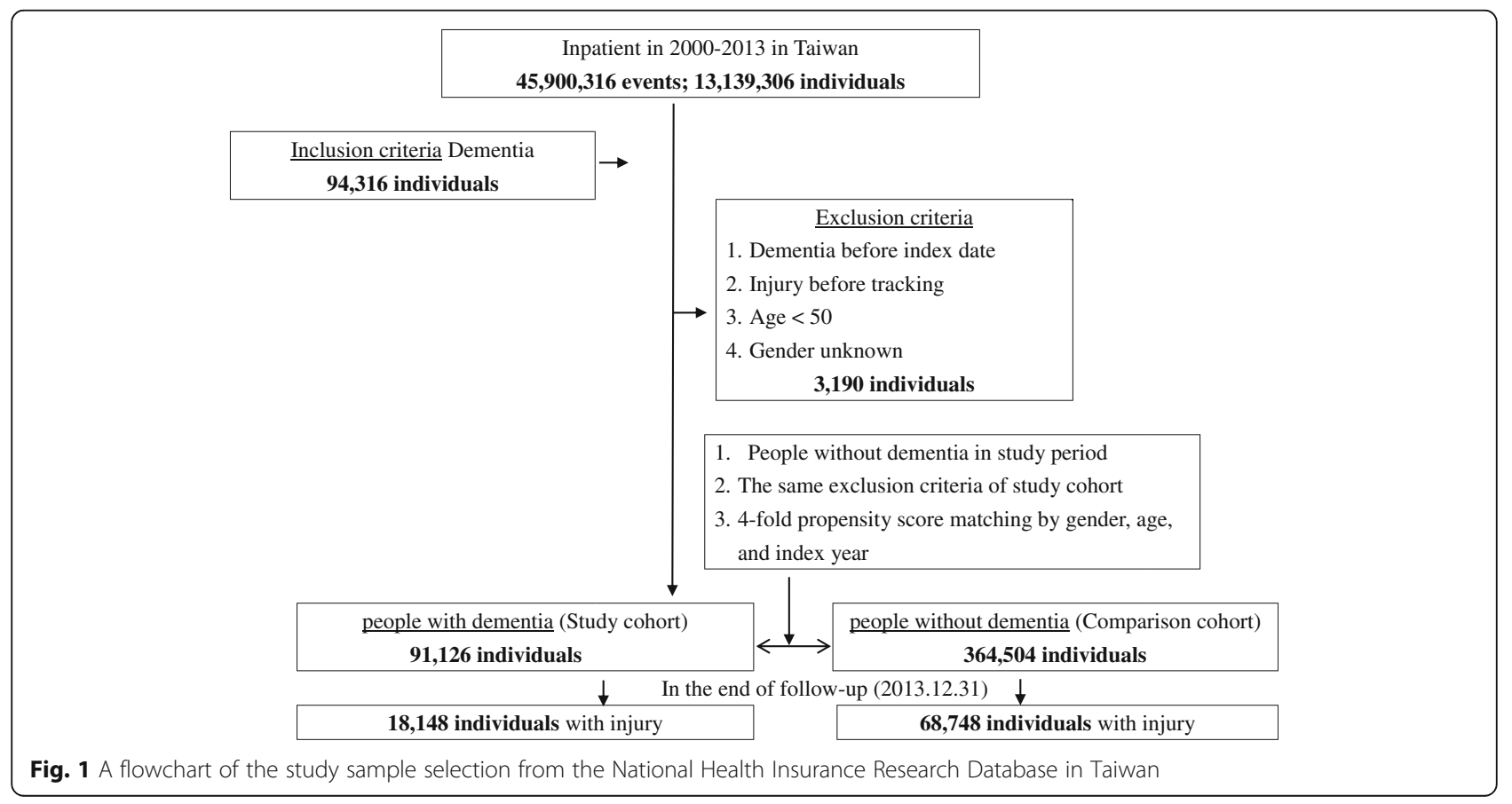


Table 1 Characteristics of people with and without dementia

\begin{tabular}{|c|c|c|c|c|c|c|c|}
\hline \multirow[t]{2}{*}{ Variables } & \multicolumn{2}{|l|}{ Total } & \multicolumn{2}{|c|}{ People with dementia } & \multicolumn{2}{|c|}{ People without dementia } & \multirow[t]{2}{*}{$p$ value } \\
\hline & $n$ & $\%$ & $n$ & $\%$ & $n$ & $\%$ & \\
\hline Total & 455,630 & & 91,126 & 20.00 & 364,504 & 80.00 & \\
\hline Gender & & & & & & & 0.999 \\
\hline Male & 237,945 & 52.22 & 47,589 & 52.22 & 190,356 & 52.22 & \\
\hline Female & 217,685 & 47.78 & 43,537 & 47.78 & 174,148 & 47.78 & \\
\hline Age group (years) & & & & & & & 0.999 \\
\hline $50-64$ & 21,660 & 4.75 & 4332 & 4.75 & 17,328 & 4.75 & \\
\hline $65-74$ & 85,675 & 18.80 & 17,135 & 18.80 & 68,540 & 18.80 & \\
\hline $75-84$ & 215,435 & 47.28 & 43,087 & 47.28 & 172,348 & 47.28 & \\
\hline$\geqq 85$ & 132,860 & 29.16 & 26,572 & 29.16 & 106,288 & 29.16 & \\
\hline Catastrophic illness & & & & & & & $<0.001$ \\
\hline Without & 370,567 & 81.33 & 71,996 & 79.01 & 298,571 & 81.91 & \\
\hline With & 85,063 & 18.67 & 19,130 & 20.99 & 65,933 & 18.09 & \\
\hline Injury outpatient/ER 1 year before index date & & & & & & & $<0.001$ \\
\hline Without & 313,474 & 68.80 & 61,083 & 67.03 & 252,391 & 69.24 & \\
\hline With & 142,156 & 31.20 & 30,043 & 32.97 & 112,113 & 30.76 & \\
\hline \multicolumn{8}{|l|}{ Comorbidity } \\
\hline Diabetes mellitus & & & & & & & $<0.001$ \\
\hline Without & 333,830 & 73.27 & 67,515 & 74.09 & 266,315 & 73.06 & \\
\hline With & 121,800 & 26.73 & 23,611 & 25.91 & 98,189 & 26.94 & \\
\hline Hypertension & & & & & & & $<0.001$ \\
\hline Without & 280,288 & 61.52 & 58,684 & 64.40 & 221,604 & 60.80 & \\
\hline With & 175,342 & 38.48 & 32,442 & 35.60 & 142,900 & 39.20 & \\
\hline Hyperlipidemia & & & & & & & $<0.001$ \\
\hline Without & 431,603 & 94.73 & 88,066 & 96.64 & 343,537 & 94.25 & \\
\hline With & 24,027 & 5.27 & 3060 & 3.36 & 20,967 & 5.75 & \\
\hline Cardiovascular disease & & & & & & & $<0.001$ \\
\hline Without & 408,717 & 89.70 & 78,975 & 86.67 & 329,742 & 90.46 & \\
\hline With & 46,913 & 10.30 & 12,151 & 13.33 & 34,762 & 9.54 & \\
\hline Chronic kidney disease & & & & & & & $<0.001$ \\
\hline Without & 412,668 & 90.57 & 85,668 & 94.01 & 327,000 & 89.71 & \\
\hline With & 42,962 & 9.43 & 5458 & 5.99 & 37,504 & 10.29 & \\
\hline Alcohol-related disease & & & & & & & $<0.001$ \\
\hline Without & 454,861 & 99.83 & 90,925 & 99.78 & 363,936 & 99.84 & \\
\hline With & 769 & 0.17 & 201 & 0.22 & 568 & 0.16 & \\
\hline
\end{tabular}

Diabetes mellitus: International Classification of Diseases, Ninth Revision, Clinical Modification (ICD-9-CM) 250; hypertension, ICD-9-CM 401.1, 401.9, 402.10, 402.90, 404.10, 404.90, 405.1, 405.9; hyperlipidemia, ICD-9-CM 272; cerebrovascular disease, ICD-9-CM 433-434, 436; chronic kidney disease, ICD-9-CM 274.1, 403-404, 440.1, 442.1, 447.3, 572.4, 580-589, 642.1, 646.2, 753); alcohol-related disease, ICD-9-CM 291, 303

$p$ value by Chi-square/Fisher exact test on category variables and $t$ test on continue variables

$E R$ emergency room

most common cause of injury in both people with dementia and people without dementia (50.15\% vs $47.47 \%)$, followed by abnormal reactions to medical procedures $(21.97 \%$ vs $23.79 \%)$ and other unintentional injuries $(10.40 \%)$ in people with dementia and traffic accidents in people without dementia (11.55\%). Unintentional injuries were most common in both people with dementia and people without dementia (98.90\% vs $98.62 \%)$.

The Kaplan-Meier analysis for the cumulative risk of injuries in individuals with and without dementia using a log-rank test showed a significant difference over the 14-year follow-up period ( $p<0.001)$ (Fig. 2). 
Table 2 Injury in people with and without dementia

\begin{tabular}{|c|c|c|c|c|c|c|c|}
\hline \multirow[t]{2}{*}{ Variables } & \multicolumn{2}{|l|}{ Total } & \multicolumn{2}{|c|}{ People with dementia } & \multicolumn{2}{|c|}{ People without dementia } & \multirow[t]{2}{*}{$p$ value } \\
\hline & $n$ & $\%$ & $n$ & $\%$ & $n$ & $\%$ & \\
\hline Total & 455,630 & & 91,126 & 20.00 & 364,504 & 80.00 & \\
\hline Injury & & & & & & & $<0.001$ \\
\hline Without & 368,734 & 80.93 & 72,978 & 80.08 & 295,756 & 81.14 & \\
\hline With & 86,896 & 19.07 & 18,148 & 19.92 & 68,748 & 18.86 & \\
\hline Injury diagnosis & & & & & & & $<0.001$ \\
\hline Fracture & 32,838 & 37.79 & 6374 & 35.12 & 26,464 & 38.49 & \\
\hline Dislocation & 826 & 0.95 & 182 & 1.00 & 644 & 0.94 & \\
\hline Sprains and strains & 1715 & 1.97 & 415 & 2.29 & 1300 & 1.89 & \\
\hline Intracranial/internal injury & 9694 & 11.16 & 2246 & 12.38 & 7448 & 10.83 & \\
\hline Open wound & 4504 & 5.18 & 1093 & 6.02 & 3411 & 4.96 & \\
\hline Injury to blood vessels & 51 & 0.06 & 6 & 0.03 & 45 & 0.07 & \\
\hline Superficial injury/contusion & 3494 & 4.02 & 826 & 4.55 & 2668 & 3.88 & \\
\hline Crushing & 185 & 0.21 & 28 & 0.15 & 157 & 0.23 & \\
\hline Foreign body entering through orifice & 1079 & 1.24 & 375 & 2.07 & 704 & 1.02 & \\
\hline Burn & 936 & 1.08 & 228 & 1.26 & 708 & 1.03 & \\
\hline Injury to nerves and spinal cord & 367 & 0.42 & 62 & 0.34 & 305 & 0.44 & \\
\hline Poisoning & 3897 & 4.48 & 901 & 4.96 & 2996 & 4.36 & \\
\hline Others injury & 27,310 & 31.43 & 5412 & 29.82 & 21,898 & 31.85 & \\
\hline Cause of injury & & & & & & & $<0.001$ \\
\hline Traffic & 5888 & 10.44 & 647 & 5.86 & 5241 & 11.55 & \\
\hline Poisoning (drugs/medicaments/biologicals) & 816 & 1.45 & 212 & 1.92 & 604 & 1.33 & \\
\hline Poisoning (solid and liquid substances/gases/vapors) & 191 & 0.34 & 41 & 0.37 & 150 & 0.33 & \\
\hline Surgical/medical care & 137 & 0.24 & 30 & 0.27 & 107 & 0.24 & \\
\hline Abnormal reaction of medical procedures & 13,221 & 23.44 & 2424 & 21.97 & 10,797 & 23.79 & \\
\hline Falls & 27,075 & 48.00 & 5533 & 50.15 & 21,542 & 47.47 & \\
\hline Burns and fires & 64 & 0.11 & 10 & 0.09 & 54 & 0.12 & \\
\hline Environment & 216 & 0.38 & 33 & 0.30 & 183 & 0.40 & \\
\hline Drowning & 8 & 0.01 & 1 & 0.01 & 7 & 0.02 & \\
\hline Suffocation & 672 & 1.19 & 238 & 2.16 & 434 & 0.96 & \\
\hline Other unintentional injuries & 4717 & 8.36 & 1147 & 10.40 & 3570 & 7.87 & \\
\hline Late effects & 1324 & 2.35 & 314 & 2.85 & 1010 & 2.23 & \\
\hline Adverse drug reaction & 1331 & 2.36 & 281 & 2.55 & 1050 & 2.31 & \\
\hline Suicide & 580 & 1.03 & 82 & 0.74 & 498 & 1.10 & \\
\hline Homicide/abuse & 168 & 0.30 & 39 & 0.35 & 129 & 0.28 & \\
\hline Intentionality of injury & & & & & & & 0.018 \\
\hline Unintentional & 55,660 & 98.67 & 10,911 & 98.90 & 44,749 & 98.62 & \\
\hline Intentional & 748 & 1.33 & 121 & 1.10 & 627 & 1.38 & \\
\hline
\end{tabular}

$p$ value by Chi-square/Fisher exact test on category variables and $t$ test on continue variables

Risk factors for overall injury

After controlling for comorbidities, Cox regression analysis showed that the risk factors for overall injury were dementia $(H R=1.070, p<0.001)$, dementia subtype (Alzheimer's disease, $\mathrm{HR}=1.104, p<0.001$ ), female gender $(\mathrm{HR}=1.100, \quad p<0.001)$, age $65-74$ years $(\mathrm{HR}=1.058, p<0.001)$, and seeking medical attention for an injury at a clinic or emergency room within the last year $(\mathrm{HR}=1.241, p<0.001)$. Catastrophic illness $(\mathrm{HR}=0.785, p<0.001)$ was not a significant risk factor for injury-related hospitalization (Table 3). 


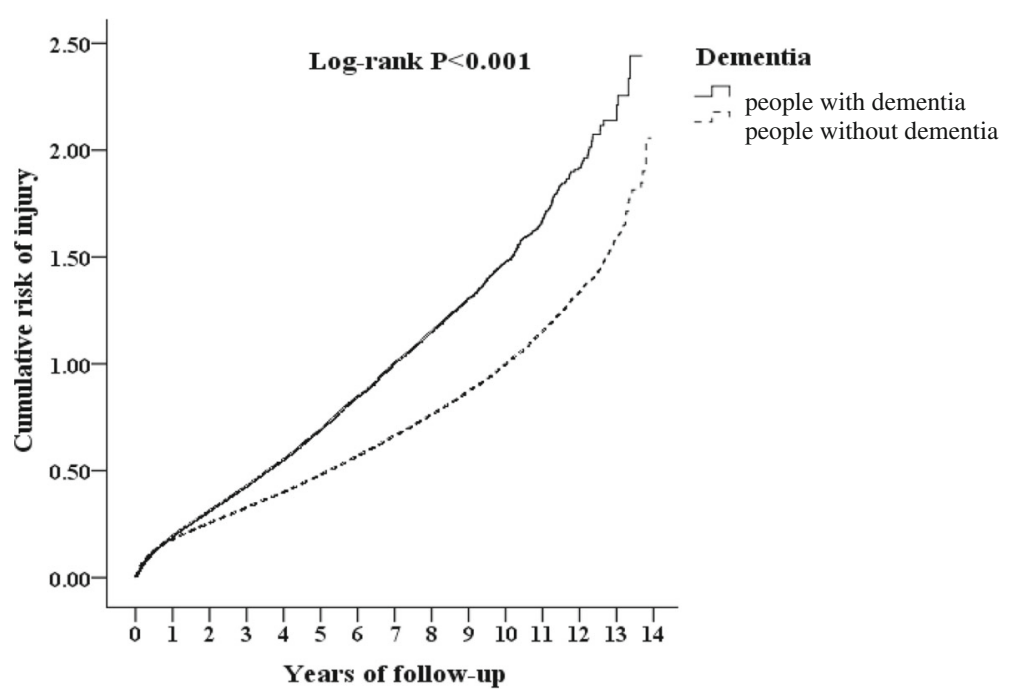

Fig. 2 Kaplan-Meier curve of the cumulative risk of injury in patients aged 50 years and over stratified by dementia with log-rank test

Table 3 Risk factors for injury using Cox regression

\begin{tabular}{|c|c|c|c|c|c|c|c|c|}
\hline Variables & Crude HR & $95 \% \mathrm{Cl}$ & $95 \% \mathrm{Cl}$ & $p$ value & Adjusted HR & $95 \% \mathrm{Cl}$ & $95 \% \mathrm{Cl}$ & $p$ value \\
\hline \multicolumn{9}{|l|}{ Dementia } \\
\hline People without dementia & Reference & & & & Reference & & & \\
\hline People with dementia & 1.083 & 1.066 & 1.101 & $<0.001$ & 1.070 & 1.052 & 1.087 & $<0.001$ \\
\hline \multicolumn{9}{|l|}{ Dementia subtype } \\
\hline Without & Reference & & & & Reference & & & \\
\hline Alzheimer disease & 1.109 & 1.088 & 1.129 & $<0.001$ & 1.104 & 1.084 & 1.125 & $<0.001$ \\
\hline Vascular dementia & 1.081 & 0.959 & 1.218 & 0.201 & 1.057 & 0.938 & 1.191 & 0.364 \\
\hline Other dementia & 1.007 & 0.976 & 1.039 & 0.674 & 1.001 & 0.940 & 1.024 & 0.062 \\
\hline \multicolumn{9}{|l|}{ Gender } \\
\hline Male & Reference & & & & Reference & & & \\
\hline Female & 1.080 & 1.066 & 1.095 & $<0.001$ & 1.100 & 1.086 & 1.115 & $<0.001$ \\
\hline \multicolumn{9}{|l|}{ Age group (years) } \\
\hline $50-64$ & Reference & & & & Reference & & & \\
\hline $65-74$ & 1.050 & 1.021 & 1.079 & 0.001 & 1.058 & 1.029 & 1.088 & $<0.001$ \\
\hline $75-84$ & 0.877 & 0.856 & 0.899 & $<0.001$ & 0.864 & 0.843 & 0.886 & $<0.001$ \\
\hline$\geqq 85$ & 0.658 & 0.641 & 0.675 & $<0.001$ & 0.630 & 0.614 & 0.647 & $<0.001$ \\
\hline \multicolumn{9}{|l|}{ Catastrophic illness } \\
\hline Without & Reference & & & & Reference & & & \\
\hline With & 0.788 & 0.775 & 0.802 & $<0.001$ & 0.785 & 0.771 & 0.799 & $<0.001$ \\
\hline \multicolumn{9}{|c|}{ Injury outpatient / ER 1 year before index date } \\
\hline Without & Reference & & & & Reference & & & \\
\hline With & 1.267 & 1.250 & 1.284 & $<0.001$ & 1.241 & 1.224 & 1.258 & $<0.001$ \\
\hline
\end{tabular}

Adjusted for comorbidities (diabetes mellitus, hypertension, hyperlipidemia, cerebrovascular disease, chronic kidney disease, alcohol-related disease) $C l$ confidence interval, $E R$ emergency room, $H R$ hazard ratio 
For the risk factors for injuries, further Cox regression analysis showed that people with dementia aged 50-64, 65-74, and 75-84 years were at an increased risk of injury-related hospitalization compared with people without dementia (HR 1.080-1.164) (Table 4).

\section{Injury type versus hospitalization risk}

We analyzed the diagnosis, cause, and intentionality of injury. We also analyzed the hospitalization risks of different types of injury with Cox regression analysis. For the injury diagnosis, people with dementia were at a higher risk of hospitalization due to a foreign body entering through an orifice, sprains and strains, and burns than were people without dementia. For the cause of injury, people with dementia were at a higher risk of hospitalization due to suffocation and accidental poisoning by drugs. In contrast, people with dementia were at a lower risk of hospitalization due to suicide and self-inflicted injury and traffic accidents than were people without dementia. Also, for the intentionality of injury, people with dementia were at a higher risk of hospitalization due to unintentional injury than were people without dementia (Table 5). Subgroup analysis of three subtypes of dementia showed that people with dementia were at a higher risk of homicide or abuse than were people without dementia, regardless of dementia subtype, including vascular dementia $(\mathrm{HR}=2.079$, $p<0.001)$, Alzheimer's disease $(\mathrm{HR}=1.156, p<0.001)$, and other dementia $(\mathrm{HR}=1.421, p<0.001)$.

\section{Discussion}

In Taiwan, the recognition, management, and support services for people with dementia has been consistent and persistent from 2000 to 2018. In 2000, the government of Taiwan started its "long-term care" policy, the goal of which was to "develop a comprehensive long-term caring system for people in need to receive services. Therefore, their independence and quality of life increased and their capability of keeping dignity and self-reliance held firm" [24]. This is still the current policy and the result of this study provides considerations and suggestions for the government of Taiwan's future plans for the policy.

\section{Risk factors for overall injury}

The risk factors for injury-related hospitalization were dementia, female gender, age 65-74 years, and seeking medical attention for an injury at a clinic or emergency room within the last year. Whilst the difference in risk of injury between people with and without dementia was statistically significant, it was a small difference being only 1.07 times higher. Previous studies showed that people with dementia were at a higher risk of injury-related hospitalization than were people without dementia [3, 25], and women were 1.1 times more likely than men to be hospitalized for an injury. Previous studies reached different conclusions on the role of gender in injury-related hospitalization. A study in Australia concluded that females with dementia were at a lower risk of injury-related hospitalization than were males [25], whereas females with dementia were at a higher risk

Table 4 Factors for injury stratified by variables listed in the table using Cox regression

\begin{tabular}{|c|c|c|c|c|c|c|c|c|c|c|}
\hline \multirow[t]{2}{*}{ Stratified } & \multicolumn{3}{|c|}{ People with dementia } & \multicolumn{3}{|c|}{ People without dementia } & \multirow[t]{2}{*}{ Ratio } & \multirow[t]{2}{*}{ Adjusted HR } & \multirow[t]{2}{*}{$95 \% \mathrm{Cl}$} & \multirow[t]{2}{*}{$p$ value } \\
\hline & Event & PYs & Rate (per $10^{5} \mathrm{PYs}$ ) & Event & PYS & Rate (per $10^{5} \mathrm{PYs}$ ) & & & & \\
\hline Total & 18,148 & $142,971.64$ & $12,693.43$ & 68,748 & $596,593.59$ & $11,523.42$ & 1.102 & 1.070 & $1.052-1.087$ & $<0.001$ \\
\hline \multicolumn{11}{|l|}{ Gender } \\
\hline Male & 9435 & $73,875.94$ & $12,771.41$ & 34,625 & $314,976.08$ & $10,992.90$ & 1.162 & 1.104 & $1.078-1.129$ & $<0.001$ \\
\hline Female & 8713 & $69,095.70$ & $12,610.05$ & 34,123 & $281,617.51$ & $12,116.79$ & 1.041 & 1.032 & $1.008-1.057$ & 0.009 \\
\hline \multicolumn{11}{|c|}{ Age group (years) } \\
\hline $50-64$ & 1531 & 9815.95 & $15,597.06$ & 5860 & $43,124.98$ & $13,588.41$ & 1.148 & 1.164 & $1.100-1.232$ & $<0.001$ \\
\hline $65-74$ & 3400 & $20,642.92$ & $16,470.54$ & 11,866 & $81,240.04$ & $14,606.10$ & 1.128 & 1.092 & $1.051-1.135$ & $<0.001$ \\
\hline $75-84$ & 8185 & $59,944.66$ & $13,654.26$ & 31,122 & $255,921.18$ & $12,160.78$ & 1.123 & 1.080 & $1.054-1.107$ & $<0.001$ \\
\hline$\geqq 85$ & 5032 & $52,568.11$ & 9572.34 & 19,900 & $216,307.39$ & 9199.87 & 1.040 & 1.012 & $0.981-1.044$ & 0.455 \\
\hline \multicolumn{11}{|c|}{ Catastrophic illness } \\
\hline Without & 14,846 & $111,309.27$ & $13,337.61$ & 56,572 & $471,309.04$ & $12,003.16$ & 1.111 & 1.065 & $1.045-1.084$ & $<0.001$ \\
\hline With & 3302 & $31,662.37$ & $10,428.78$ & 12,176 & $125,284.55$ & 9718.68 & 1.073 & 1.118 & $1.076-1.163$ & $<0.001$ \\
\hline \multicolumn{11}{|c|}{ Injury outpatient/ER 1 year before index date } \\
\hline Without & 10,585 & $51,095.49$ & $20,716.11$ & 41,104 & $209,544.31$ & $19,615.90$ & 1.056 & 1.055 & $1.033-1.078$ & $<0.001$ \\
\hline With & 7563 & $91,876.15$ & 8231.73 & 27,644 & $387,049.28$ & 7142.24 & 1.153 & 1.093 & $1.065-1.121$ & $<0.001$ \\
\hline
\end{tabular}

Adjusted for comorbidities (diabetes mellitus, hypertension, hyperlipidemia, cerebrovascular disease, chronic kidney disease, alcohol-related disease) $\mathrm{Cl}$ confidence interval, ER emergency room, $H R$ hazard ratio, $P Y s$ person-years 
Table 5 Factors for injury subgroup stratified using Cox regression

\begin{tabular}{|c|c|c|c|c|c|c|c|c|c|c|}
\hline \multirow{2}{*}{$\begin{array}{l}\text { Dementia } \\
\text { Injury subgroup }\end{array}$} & \multicolumn{3}{|c|}{ People with dementia } & \multicolumn{3}{|c|}{ People without dementia } & \multirow[t]{2}{*}{ Ratio } & \multirow[t]{2}{*}{ Adjusted HR } & \multirow[t]{2}{*}{$95 \% \mathrm{Cl}$} & \multirow[t]{2}{*}{$p$ value } \\
\hline & Event & PYs & Rate (per $10^{5} \mathrm{PYs}$ ) & Event & PYS & Rate (per $10^{5} \mathrm{PYs}$ ) & & & & \\
\hline \multicolumn{11}{|l|}{ Injury diagnosis } \\
\hline Fracture & 6374 & $142,971.64$ & 4458.23 & 26,464 & $596,593.59$ & 4435.85 & 1.005 & 0.992 & $0.965-1.020$ & 0.573 \\
\hline Sprains and strains & 415 & $142,971.64$ & 290.27 & 1300 & $596,593.59$ & 217.90 & 1.332 & 1.316 & $1.177-1.471$ & $<0.001$ \\
\hline $\begin{array}{l}\text { Intracranial/internal } \\
\text { injury }\end{array}$ & 2246 & $142,971.64$ & 1570.94 & 7448 & $596,593.59$ & 1248.42 & 1.258 & 1.204 & $1.148-1.263$ & $<0.001$ \\
\hline Open wound & 1093 & $142,971.64$ & 764.49 & 3411 & $596,593.59$ & 571.75 & 1.337 & 1.171 & $1.093-1.255$ & $<0.001$ \\
\hline $\begin{array}{l}\text { Foreign body entering } \\
\text { through orifice }\end{array}$ & 375 & $142,971.64$ & 262.29 & 704 & $596,593.59$ & 118.00 & 2.223 & 2.202 & $1.939-2.499$ & $<0.001$ \\
\hline Burn & 228 & $142,971.64$ & 159.47 & 708 & $596,593.59$ & 118.67 & 1.344 & 1.296 & $1.115-1.507$ & 0.001 \\
\hline Poisoning & 901 & $142,971.64$ & 630.19 & 2996 & $596,593.59$ & 502.18 & 1.255 & 1.206 & $1.118-1.300$ & $<0.001$ \\
\hline \multicolumn{11}{|l|}{ Cause of injury } \\
\hline Traffic & 647 & $142,971.64$ & 452.54 & 5241 & $596,593.59$ & 878.49 & 0.515 & 0.510 & $0.470-0.553$ & $<0.001$ \\
\hline $\begin{array}{l}\text { Poisoning (drugs/ } \\
\text { medicaments/ } \\
\text { biologicals) }\end{array}$ & 212 & $142,971.64$ & 148.28 & 604 & $596,593.59$ & 101.24 & 1.465 & 1.485 & $1.268-1.739$ & $<0.001$ \\
\hline Falls & 5533 & $142,971.64$ & 3870.00 & 21,542 & $596,593.59$ & 3610.83 & 1.072 & 1.076 & $1.044-1.108$ & $<0.001$ \\
\hline Suffocation & 238 & $142,971.64$ & 166.47 & 434 & $596,593.59$ & 72.75 & 2.288 & 2.301 & $1.961-2.701$ & $<0.001$ \\
\hline Suicide & 82 & $142,971.64$ & 57.35 & 498 & $596,593.59$ & 83.47 & 0.687 & 0.670 & $0.530-0.848$ & 0.001 \\
\hline Homicide/abuse & 39 & $142,971.64$ & 27.28 & 129 & $596,593.59$ & 21.62 & 1.262 & 1.107 & $0.770-1.590$ & 0.584 \\
\hline \multicolumn{11}{|l|}{ Intentionality of injury } \\
\hline Unintentional & 10,911 & $142,971.64$ & 7631.58 & 44,749 & $596,593.59$ & 7500.75 & 1.017 & 1.018 & $1.007-1.040$ & 0.009 \\
\hline Intentional & 121 & $142,971.64$ & 84.63 & 627 & $596,593.59$ & 105.10 & 0.805 & 0.764 & $0.628-0.930$ & 0.007 \\
\hline
\end{tabular}

Adjusted for comorbidities (diabetes mellitus, hypertension, hyperlipidemia, cerebrovascular disease, chronic kidney disease, alcohol-related disease)

$C l$ confidence interval, $E R$ emergency room, $H R$ hazard ratio, $P Y$ s person-years

of falls and unintentional drug poisoning than were males $[3,13]$. This study showed that the age group of $65-74$ years was associated with a 1.058-fold higher risk of injury-related hospitalization than the age group of 50-64 years, whereas the age group of 75 years or above was associated with a lower risk of injury-related hospitalization than the age group of 50-64 years. A retrospective study on people with dementia versus people without dementia in Australia showed that individuals aged 65 and above were at a higher risk of injuries than were those aged 50-64 years; in particular, those aged 85 and above were 1.43 times more likely to have an injury than those aged 50-64 years [25], in contrast to the findings of this study which may be a result of where the study subjects lived (country) and the ethnicity and lifestyle of the subjects. Moreover, the Australian study used the ICD-10-CM diagnostic codes, whereas this study used the ICD-9-CM codes. Further research is needed for a more in-depth analysis.

\section{Injury subtypes and hospitalization risk in people with and without dementia Suffocation and foreign bodies}

According to the results of the study, people with dementia were 2.301 times more likely to be admitted for suffocation than were people without dementia. Individuals aged 65 years and above were more likely to die of suffocation (mostly due to food) than were those in other age groups $[11,26]$. Many studies have shown that the risk factors for food-related suffocation include liquid or semi-solid food, poor dentition, alcohol, sedatives, and antipsychotics [11, 26-29].

In addition, foreign bodies may cause suffocation. A Japanese study analyzed the ingestion of inedible substances by psychiatric hospitalized people and showed that people with dementia were at the greatest risk of ingesting foreign bodies, followed by people with schizophrenia. Most cases involved the unintentional ingestion of foreign bodies regardless of dementia subtype, such as Alzheimer's disease and vascular dementia. The most common foreign bodies ingested were diapers and gauze, and this occurred in the morning and before meals [12,30]. People with dementia were prone to unintentional ingestion due to $\operatorname{cog}$ nitive impairment; ingestion of inedible substances was a symptom of hyperorality in people with dementia [12, 31, 32]. Another study showed that people with dementia tend to have swallowing problems. As a result, we need to prevent people with dementia from swallowing foreign bodies, enhance their oral exercise training, swallow 
therapy, and dietary modification, and monitor their sedatives and antipsychotics intake.

\section{Accidental poisoning by drugs, medicinal substances, and biologicals}

People with dementia were 1.485 times more likely to be hospitalized for unintentional drug poisoning than were people without dementia, which was consistent with the findings of the Australian study [13]. The causes of unintentional overdose in elderly populations were the regular use of two or more medications, over-the-counter drugs or supplements, drug interactions, incorrect route of administration, no monitoring of drug concentrations, lack of knowledge about drugs, improper drug storage, sharing drugs with others, and adverse drug reactions [33-36]. People with dementia may have compliance problems, including how to take drugs as directed, and poor knowledge about drugs, or they may be unable to notice or handle adverse drug reactions, may mistake inedible substances (such as detergents) as drugs, and may take drugs via an incorrect route of administration $[14,35]$ because of declining memory, computational capability, judgment, and attention [2], resulting in an increased risk of hospitalization due to unintentional drug poisoning. To minimize these risks, drugs should be stored properly (drugs should be kept away from other similarlooking substances, and it should be ensured that the packaging is easy to identify and not broken), and a caregiver should become involved to help manage the medications $[13,33,34]$ and monitor their adverse drug reactions.

\section{Accidental falls}

People with dementia were 1.076 times more likely to be hospitalized for accidental falls than were people without dementia. The recent literature and systematic reviews suggest that people with dementia are 2-8 times more likely to fall than are healthy individuals, with the former having an incidence of approximately $60-80 \%$ per year $[15,16,37-40]$. A prospective case-control study showed that elderly populations with cognitive impairment were two times more likely to fall than were those without cognitive impairment [41]. Even people with mild cognitive impairment (MCI) were at a higher risk of falls [40] and were 1.72 times more likely to fall than were those without cognitive impairment [42].

The risk factors for falls in people with dementia include the following: 1) cognitive impairment since people with dementia experience neurological and cognitive changes in the early stage of dementia, which impairs performance (attention, planning, orientation) and then gait (pace, step, dynamic balance); 2) motor disorders, including gait and balance disorders, and muscle weakness; and 3) behavioral disorders, including wandering and aggressive behaviors. People with dementia are also at risk of falls because they can potentially misjudge environmental hazards, overestimate their own ability, or suffer memory impairment. Antipsychotics are usually prescribed to improve psychiatric and behavioral symptoms in people with behavioral disorders, but these drugs may increase the risk of falls; finally, the presence of other health problems (such as orthostatic hypotension) can also increase the risk of falls $[15,40,43-45]$. As a result, it is crucial to understand the risk factors for falls in each individual person with dementia and provide much needed fall-prevention training.

\section{Homicide or abuse}

People with dementia along with any dementia subtypevascular dementia, Alzheimer's disease, and other dementia-were 1.156 to 2.079 times more likely to be hospitalized due to homicide or abuse than were people without dementia. Studies conducted in Amsterdam, the US, Ireland, London, Stockholm, and Kyoto showed that 5\% to $55 \%$ of elderly people with dementia suffered abuse, which was significantly higher than the percentage observed in the general population $(3.2-27.5 \%)[17,18]$. In the US, 500,000 to 2.5 million individuals aged 60 and above suffer abuse, especially at the hands of their spouse or children [46]. Abuse may be psychological, physical, or sexual [47], but the most common form is psychological abuse ( 27.9-62.3\%) [48]. Moreover, studies have shown that, for people with dementia, verbal abuse is most common (27-40\%) [47], followed by physical abuse (3.523.1\%) [48]. Unfortunately, we were unable to conduct a detailed analysis of abuse because the database contained no information on the different types of abuse.

People with dementia are more likely to suffer abuse than people without dementia for the following reasons: 1) confrontations between caregivers and people with dementia exhibiting psychological or behavioral symptoms, such as agitation and aggression; and 2) caregiver burden and stress [48]. For example, a survey in Australia surveyed homicidal ideation among primary caregivers of people with dementia and showed that $28.6 \%$ of primary caregivers actively or passively wished that the person would die [49]. Besides preventing the abuse of people with dementia, we need to acknowledge and provide support for the burden, stress, and emotional needs of the primary caregivers. This study may have underestimated the incidence rates of homicide or abuse because only severe homicide or abuse cases that resulted in hospitalization and were reported to government agencies were included in this study; cases where people with dementia did not seek medical attention or sought medical attention at clinics or emergency rooms were not reported. Thus, further research is needed to investigate this topic.

\section{Suicide and self-inflicted injury}

People with dementia were at a lower risk of suicide-related hospitalization than people without dementia, which may 
be a result of the cognitive and performance impairments of people with dementia.

Some researchers believe that people with dementia are at risk of suicide in the early stage of dementia, likely because they realize that they will become disabled and are concerned about the course of their disease and losing their independence. However, they still have the insight that their cognitive function will deteriorate and are concerned about the physical and economic burdens to their family; thus, they are at risk of suicide [19-21, 50]. As the disease progresses and insight and performance decline, people with moderate to severe dementia are less capable of preparing and planning a suicide, which reduces the risk of suicide [21, 22].

\section{Traffic accidents}

People with dementia were at a lower risk of traffic-related hospitalization than were people without dementia, which may be a result of the nature of the study subjects. The lower risk could possibly be due to the fact that a person with dementia may be less likely to go outside alone, without being accompanied by a family member or caregiver, compared with people without dementia. Hospitalized people with dementia may have been diagnosed with dementia for a long time, and their caregivers or healthcare providers would have reminded or asked them to stop driving, or those patients may no longer drive due to limited ability. A study in Australia showed that people with dementia were at a lower risk of traffic accidents within 3 years after hospitalization than were people without dementia (odds ratio 0.07 ), consistent with the findings of this study [5].

For people with dementia, cognitive impairment will affect vision, judgment, problem solving and decision-making skills, perception, and attention [4,51, 52], which makes them prone to traffic accidents. However, recent studies have reached different conclusions. Some publications have shown that people with MCI or with dementia are 2-10 times more likely to die from traffic accidents while driving or riding motorcycles than are people without dementia $[4,53,54]$. However, some studies have shown no significant difference in the traffic accident rates between people with and without dementia $[23,55,56]$. Some studies reported that caregivers and healthcare providers asked people with dementia to stop driving for safety concerns $[57,58]$. In addition, disease progression will severely affect memory, response, perception, the ability to perform simple tasks, and eventually the ability to drive; thus, people with dementia will stop driving 2 to 3 years after developing these symptoms $[5,59]$.

\section{Limitations}

The present study possesses some limitations of note. The target population of this study were hospitalized people with and without dementia due to injury and who were aged 50 years and above. The result of this study cannot be generalized to people who are below the age of 50 years or outpatient and emergency patients. As a result, future research should further explore the risks and risk factors for people with and without dementia who are aged below 50 years and outpatient and emergency patients.

\section{Conclusion}

The risk factors for injury-related hospitalization were dementia (especially Alzheimer's disease), female gender, age 65-74 years, and seeking medical attention for an injury at a clinic or emergency room within the last year. For different types of injury, people with dementia were at a higher risk of hospitalization due to accidental drug poisoning, accidental falls, accidents caused by submersion, suffocation, and homicide or abuse than were people without dementia. The results of this study will serve as a reference for developing injury prevention and intervention programs for people with dementia, including guidance for caregiver assistance in drug management and how to prevent falls and suffocation caused by foreign bodies or food. In addition, government agencies should pay attention to the abuse suffered by people with dementia and should actively intervene and assist in handling related problems.

\section{Abbreviations \\ Cl: Confidence interval; HR: Hazard ratio; ICD-9-CM: International Classification of Diseases, Ninth Revision, Clinical Modification; IRB: Institutional Review Board; MCl: Mild cognitive impairment; NHI: National Health Insurance; NHIRD: National Health Insurance Research Database; TSGH: Tri-Service General Hospital \\ Acknowledgements \\ The study was supported by the National Defense Medical Center and Tri- Service General Hospital (TSGH-C107-004). \\ Funding \\ Not applicable. \\ Availability of data and materials \\ Not applicable. \\ Authors' contributions \\ $\mathrm{RC}$ and KRC conceived of and designed the study, and provided data acquisition, analysis and interpretation of data, and drafted the manuscript. WCC, CCK, CHC, DL, and HLC contributed to the analysis and interpretation of data, and revised the manuscript critically for important intellectual content. All authors read and approved the final manuscript.}

Ethics approval and consent to participate

This study was approved by the Joint Institutional Review Board of the TriService General Hospital (TSGH IRB no. 1-105-05-142).

Consent for publication

All authors approved the manuscript for submission.

Competing interests

The authors declare that they have no competing interests.

\section{Publisher's Note}

Springer Nature remains neutral with regard to jurisdictional claims in published maps and institutional affiliations. 


\section{Author details}

'Department of Nursing, Taipei Medical University-Shuang Ho Hospital, No.291, Zhongzheng Rd., Zhonghe District, Taipei 23561, Taiwan. ${ }^{2}$ School of Nursing, College of Nursing, Taipei Medical University, No.250, Wu-Hsing Street, Taipei 11031, Taiwan. ${ }^{3}$ Department of Medical Research, Tri-Service General Hospital, No.325, Section 2, Cheng-Kung Road, Neihu District, Taipei 11490, Taiwan. ${ }^{4}$ Graduate Institute of Life Sciences, National Defense Medical Center, No.161, Section 6, Min-Chuan East Road, Neihu District, Taipei 11490, Taiwan. ${ }^{5}$ School of Public Health, National Defense Medical Center, No.161, Section 6, Min-Chuan East Road, Neihu District, Taipei 11490, Taiwan. ${ }^{6}$ Department of Nursing, Wan Fang Hospital, Taipei Medical University, No.111, Sec. 3, Xinglong Rd., Taipei 11696, Taiwan. ${ }^{7}$ Taiwanese Injury Prevention and Safety Promotion Association (TIPSPA), Taipei, Taiwan. ${ }^{8}$ School of Gerontology Health Management, College of Nursing, Taipei Medical University, No.250, Wu-Hsing Street, Taipei 11031, Taiwan. ${ }^{9}$ Psychiatric Research Center, Taipei Medical University Hospital, No.252, Wuxing St, Xinyi District, Taipei 110, Taiwan.

\section{Received: 5 March 2018 Accepted: 10 October 2018}

\section{Published online: 30 October 2018}

\section{References}

1. Prince M, Comas-Herrera A, Knapp M, Guerchet M, Karagiannidou M. World Alzheimer Report 2016 Improving healthcare for people living with dementia coverage, Quality and costs now and in the future 2016.

2. Cerejeira J, Lagarto L, Mukaetova-Ladinska EB. Behavioral and psychological symptoms of dementia. Front Neurol. 2012;3:73.

3. Meuleners LB, Fraser ML, Bulsara MK, Chow K, Ng JQ. Risk factors for recurrent injurious falls that require hospitalization for older adults with dementia: a population based study. BMC Neurol. 2016;16(1):188.

4. Petersen JD, Siersma V, Nielsen $C T$, Vass M, Waldorff FB. Dementia and traffic accidents: a Danish register-based cohort study. JMIR Res protocol. 2016;5(3):e191.

5. Meuleners LB, Ng J, Chow K, Stevenson M. Motor vehicle crashes and dementia: a population-based study. J Am Geriatr Soc. 2016;64(5):1039-45.

6. Pinidbunjerdkool A, Saengwanitch S, Sithinamsuwan P. Behavioral and psychological symptoms of dementia. J Med Assoc Thail. 2014;97(Suppl 2): S168-S74.

7. Ballard C, Corbett A, Chitramohan R, Aarsland D. Management of agitation and aggression associated with Alzheimer's disease: controversies and possible solutions. Curr Opin Psychiatry. 2009;22(6):532-40.

8. Lövheim H, Sandman P-O, Karlsson S, Gustafson Y. Behavioral and psychological symptoms of dementia in relation to level of cognitive impairment. Int Psychogeriatr. 2008;20(4):777-89.

9. Hofman K, Primack A, Keusch G, Hrynkow S. Addressing the growing burden of trauma and injury in low-and middle-income countries. Am J Public Health. 2005;95(1):13-7.

10. Statistics $\mathrm{NCFH}$. International classification of diseases, Ninth revision, clinical modification (ICD-9-CM). 2017.

11. Kramarow E, Warner M, Chen L-H. Food-related choking deaths among the elderly. Inj Prev. 2014;20(3):200-3.

12. Yayama S, Tanimoto C, Suto S, Matoba K, Kajiwara T, Inoue M, et al. Analysis of inedible substance ingestion at a Japanese psychiatric hospital. Psychogeriatrics. 2017;17(5):292-9.

13. Mitchell R, Harvey LA, Brodaty H, Draper B, Close JC. Dementia and intentional and unintentional poisoning in older people: a 10 year review of hospitalization records in New South Wales, Australia. Int Psychogeriatr. 2015;27(11):1757-68.

14. Woolf A, Fish S, Azzara C, Dean D. Serious poisonings among older adults: a study of hospitalization and mortality rates in Massachusetts 1983-85. Am J Public Health. 1990;80(7):867-9.

15. Härlein J, Dassen T, Halfens RJ, Heinze C. Fall risk factors in older people with dementia or cognitive impairment: a systematic review. J Adv Nurs. 2009;65(5):922-33.

16. Allan LM, Ballard CG, Rowan EN, Kenny RA. Incidence and prediction of falls in dementia: a prospective study in older people. PLoS One. 2009;4(5):e5521.

17. Yan E, Kwok T. Abuse of older Chinese with dementia by family caregivers: an inquiry into the role of caregiver burden. Int J Geriatr Psychiatry. 2011;26(5):527-35.

18. Cooper C, Selwood A, Livingston G. The prevalence of elder abuse and neglect: a systematic review. Age Ageing. 2008;37(2):151-60.

19. Erlangsen A, Zarit SH, Conwell Y. Hospital-diagnosed dementia and suicide: a longitudinal study using prospective, nationwide register data. Am J Geriatr Psychiatry. 2008;16(3):220-8.
20. Draper B, Peisah C, Snowdon J, Brodaty H. Early dementia diagnosis and the risk of suicide and euthanasia: Elsevier; 2010;6(1):75-82.

21. Seyfried LS, Kales HC, Ignacio RV, Conwell Y, Valenstein M. Predictors of suicide in patients with dementia. Alzheimers Dement. 2011;7(6):567-73.

22. Cipriani G, Vedovello M, Lucetti C, Di Fiorino A, Nuti A. Dementia and suicidal behavior. Aggress Violent Behav. 2013;18(6):656-9.

23. Orriols L, Avalos-Fernandez M, Moore N, Philip P, Delorme B, Laumon B, et al. Long-term chronic diseases and crash responsibility: a record linkage study. Accid Anal Prev. 2014;71:137-43.

24. Welfare MoHa. Long-term care. 2018.

25. Meuleners LB, Hobday MB. A population-based study examining injury in older adults with and without dementia. J Am Geriatr Soc. 2017;65(3):520-5.

26. Berzlanovich AM, Fazeny-Dörner B, Waldhoer T, Fasching P, Keil W. Foreign body asphyxia: a preventable cause of death in the elderly. Am J Prev Med. 2005:28(1):65-9.

27. Nikolić S, Živković V, Dragan B, Juković F. Laryngeal choking on food and acute ethanol intoxication in adults—an autopsy study. J Forensic Sci. 2011:56(1):128-31.

28. Dolkas L, Stanley C, Smith AM, Vilke GM. Deaths associated with choking in San Diego county. J Forensic Sci. 2007:52(1):176-9.

29. Inamasu J, Miyatake S, Tomioka H, Shirai T, Ishiyama M, Komagamine J, et al. Cardiac arrest due to food asphyxiation in adults: resuscitation profiles and outcomes. Resuscitation. 2010;81(9):1082-6.

30. Cullen P, Abid F, Patel A, Coope B, Ballard C. Eating disorders in dementia. Int J Geriatr Psychiatry. 1997;12(5):559-62.

31. Burns A, Jacoby R, Levy R. Psychiatric phenomena in Alzheimer's disease. IV: disorders of behaviour. Br J Psychiatry. 1990;157(1):86-94

32. Ossenkoppele R, Pijnenburg YA, Perry DC, Cohn-Sheehy BI, Scheltens NM, Vogel JW, et al. The behavioural/dysexecutive variant of Alzheimer's disease: clinical, neuroimaging and pathological features. Brain. 2015;138(9):2732-49.

33. Elliott RA. Problems with medication use in the elderly: an Australian perspective. J Pharm Pract Res. 2006;36(1):58-66.

34. Klein-Schwartz W, Oderda GM. Poisoning in the elderly. Drugs Aging. 1991; 1(1):67-89.

35. Morgan TK, Williamson M, Pirotta M, Stewart K, Myers SP, Barnes J. A national census of medicines use: a 24-hour snapshot of Australians aged 50 years and older. Med J Aust. 2012;196(1):50-3.

36. Douglas A, Letts L, Richardson J. A systematic review of accidental injury from fire, wandering and medication self-administration errors for older adults with and without dementia. Arch Gerontol Geriatr. 2011;52(1):e1-e10.

37. Härlein J, Halfens RJ, Dassen T, Lahmann NA. Falls in older hospital inpatients and the effect of cognitive impairment: a secondary analysis of prevalence studies. J Clin Nurs. 2011;20(1-2):175-83.

38. Van Doorn C, Gruber-Baldini AL, Zimmerman S, Richard Hebel J, Port CL, Baumgarten $\mathrm{M}$, et al. Dementia as a risk factor for falls and fall injuries among nursing home residents. J Am Geriatr Soc. 2003;51(9):1213-8.

39. Oliver D, Daly F, Martin FC, McMurdo ME. Risk factors and risk assessment tools for falls in hospital in-patients: a systematic review. Age Ageing. 2004; 33(2):122-30.

40. Lach HW, Harrison BE, Phongphanngam S. Falls and fall prevention in older adults with early-stage dementia: an integrative review. Res Gerontol Nurs. 2016;10(3):139-48.

41. Taylor ME, Lord SR, Delbaere K, Mikolaizak AS, Close JC. Physiological fall risk factors in cognitively impaired older people: a one-year prospective study. Dement Geriatr Cogn Disord. 2012;34(3-4):181-9.

42. Delbaere K, Kochan NA, Close JC, Menant JC, Sturnieks DL, Brodaty H, et al. Mild cognitive impairment as a predictor of falls in community-dwelling older people. Am J Geriatr Psychiatry. 2012;20(10):845-53.

43. Strubel D, Jacquot J, Martin-Hunyadi C, editors. Dementia and falls. Annales de readaptation et de medecine physique: revue scientifique de la Societe francaise de reeducation fonctionnelle de readaptation et de medecine physique; 2001.

44. Shaw F. Prevention of falls in older people with dementia. J Neural Transm. 2007;114(10):1259-64.

45. Sheridan PL, Hausdorff JM. The role of higher-level cognitive function in gait: executive dysfunction contributes to fall risk in Alzheimer's disease. Dement Geriatr Cogn Disord. 2007;24(2):125-37.

46. Friedman LS, Avila S, Tanouye K, Joseph K. A case-control study of severe physical abuse of older adults. J Am Geriatr Soc. 2011;59(3):417-22.

47. Cooper C, Selwood A, Blanchard M, Walker Z, Blizard R, Livingston G. Abuse of people with dementia by family carers: representative cross sectional survey. BMJ. 2009;338:b155 
48. Dong $X$, Chen R, Simon MA. Elder abuse and dementia: a review of the research and health policy. Health Aff. 2014;33(4):642-9.

49. O'Dwyer ST, Moyle W, Taylor T, Creese J, Zimmer-Gembeck MJ. Homicidal ideation in family carers of people with dementia. Aging Ment Health. 2016; 20(11):1174-81.

50. Lim WS, Rubin EH, Coats M, Morris JC. Early-stage Alzheimer disease represents increased suicidal risk in relation to later stages. Alzheimer Dis Assoc Disord. 2005;19(4):214-9.

51. Wagnera JT, Mürib RM, Nefc T, Mosimannc UP. Cognition and driving in older persons. Risk. 2011;5:8.

52. Taylor $\mathrm{BD}$, Tripodes $\mathrm{S}$. The effects of driving cessation on the elderly with dementia and their caregivers. Accid Anal Prev. 2001;33(4):519-28.

53. Friedland RP, Koss E, Kumar A, Gaine S, Metzler D, Haxby JV, et al. Motor vehicle crashes in dementia of the Alzheimer type. Ann Neurol. 1988;24(6): 782-6.

54. Tuokko H, Tallman K, Beattie BL, Cooper P, Weir J. An examination of driving records in a dementia clinic. J Gerontol Ser B Psychol Sci Soc Sci. 1995;50(3): S173-S81.

55. Man-Son-Hing M, Marshall SC, Molnar FJ, Wilson KG. Systematic review of driving risk and the efficacy of compensatory strategies in persons with dementia. J Am Geriatr Soc. 2007;55(6):878-84.

56. Trobe JD, Waller PF, Cook-Flannagan CA, Teshima SM, Bieliauskas LA. Crashes and violations among drivers with Alzheimer disease. Arch Neurol. 1996;53(5):411-6.

57. Seiler S, Schmidt H, Lechner A, Benke T, Sanin G, Ransmayr G, et al. Driving cessation and dementia: results of the prospective registry on dementia in Austria (PRODEM). PLoS One. 2012;7(12):e52710.

58. Carr DB, O'Neill D. Mobility and safety issues in drivers with dementia. Int Psychogeriatr. 2015;27(10):1613-22.

59. Gilley DW, Wilson RS, Bennett DA, Stebbins GT, Bernard BA, Whalen ME, et al. Cessation of driving and unsafe motor vehicle operation by dementia patients. Arch Intern Med. 1991;151(5):941-6.

Ready to submit your research? Choose BMC and benefit from:

- fast, convenient online submission

- thorough peer review by experienced researchers in your field

- rapid publication on acceptance

- support for research data, including large and complex data types

- gold Open Access which fosters wider collaboration and increased citations

- maximum visibility for your research: over $100 \mathrm{M}$ website views per year

At BMC, research is always in progress.

Learn more biomedcentral.com/submissions 